\title{
Abdominal muscle recruitment and PEEPi during bronchoconstriction in chronic obstructive pulmonary disease
}

\author{
Massimo Gorini, Gianni Misuri, Roberto Duranti, Iacopo Iandelli, Marco Mancini, \\ Giorgio Scano
}

\begin{abstract}
Background - It has been recently shown that, when breathing at rest, many patients with severe chronic obstructive pulmonary disease (COPD) contract abdominal muscles during expiration, and that this contraction is an important determinant of positive end expiratory alveolar pressure (PEEPi). In this study the effects of acute bronchoconstriction on abdominal muscle recruitment in patients with severe COPD were studied, together with the consequence of abdominal muscle action on chest wall mechanics.
\end{abstract}

Methods - Breathing pattern, pleural (PPL) and gastric (PGA) pressures, and changes in abdomen anteroposterior (AP) diameter were studied in 14 patients with COPD (mean forced expiratory volume in one second $\left(\mathrm{FEV}_{1}\right) 1.06(0.08)$ 1) under control conditions and during histamineinduced bronchoconstriction.

Results - The analysis of plots of PGA versus the AP diameter of the abdomen revealed that during maximal bronchoconstriction (decrease in $\mathrm{FEV}_{1}$ of $\mathbf{3 4 . 8 \%}$ (95\% confidence intervals (CI) 29.9 to 39.7 )) the expiratory rise in PGA increased significantly whereas end expiratory abdomen AP diameter decreased, indicating marked abdominal muscle recruitment. As a consequence, the rib cage compartment accounted for all of the volume of hyperinflation during bronchoconstriction (mean value $0.661,95 \%$ CI 0.49 to 0.83). Positive end expiratory alveolar pressure during progressive bronchoconstriction was related directly to the expiratory rise in PGA and inversely to the expiratory time.

Conclusions - The results indicate that, in patients with severe COPD, the abdominal muscles are recruited during acute bronchoconstriction. This recruitment probably preserves diaphragm length at the beginning of inspiratory muscle contraction despite the hyperinflation, and contributes significantly to positive end expiratory alveolar pressure. The degree of dynamic pulmonary hyperinflation during bronchoconstriction can be overestimated if abdominal muscle contraction is not assessed.

(Thorax 1997;52:355-361)

Keywords: expiratory muscles, acute airway obstruction, dynamic pulmonary hyperinflation.
It has been recently shown that, when breathing at rest, many patients with severe chronic obstructive pulmonary disease (COPD) contract the abdominal muscles during expiration and relax them in the first part of inspiration..$^{1-4}$ When breathing at rest abdominal muscle contraction during expiration is an important determinant of positive end expiratory alveolar pressure in these patients. ${ }^{24}$

Attacks of acute bronchoconstriction often occur in patients with COPD when exposed to air pollutants, irritant fumes, and during respiratory infections. ${ }^{5}$ Smooth muscle contraction and airway inflammation are generally considered prominent mechanisms of increased airway obstruction during acute exacerbations of disease. ${ }^{6}$ The effects of acute bronchoconstriction on chest wall mechanics, however, have been studied in young, asymptomatic asthmatic patients ${ }^{7}$ but not in patients with COPD and severe airflow obstruction.

We have therefore investigated the effects of acute bronchoconstriction on abdominal muscle recruitment, and analysed the potential consequence of abdominal muscle action on chest wall mechanics and positive end expiratory alveolar pressure (PEEPi) in patients with severe COPD.

\section{Methods}

SUBJECTS

The study was performed in 14 male outpatients with stable COPD. ${ }^{8}$ Inclusion criteria to the study were severe airflow obstruction (forced expiratory volume in one second $\left(\mathrm{FEV}_{1}\right)<50 \%$ predicted) and age $<75$ years. The exclusion criteria were $\mathrm{FEV}_{1}<0.8$ l, left ventricular dysfunction, neuromuscular disorders, neoplasia, thoracic surgery, and moderate to severe obesity (body weight $>130 \%$ of ideal weight ${ }^{9}$ ). Each patient had been in a clinically stable condition for at least four weeks before the study. All patients gave informed consent to the protocol as approved by the institution's ethics committee.

\section{MEASUREMENTS}

All patients were studied while sitting comfortably in a high-backed armchair with a firm back and headrest. Each patient breathed through a mouthpiece, wearing a nose clip. Spirometric tests were performed according to standard technique using a water-sealed spirometer (Godart); functional residual capacity 


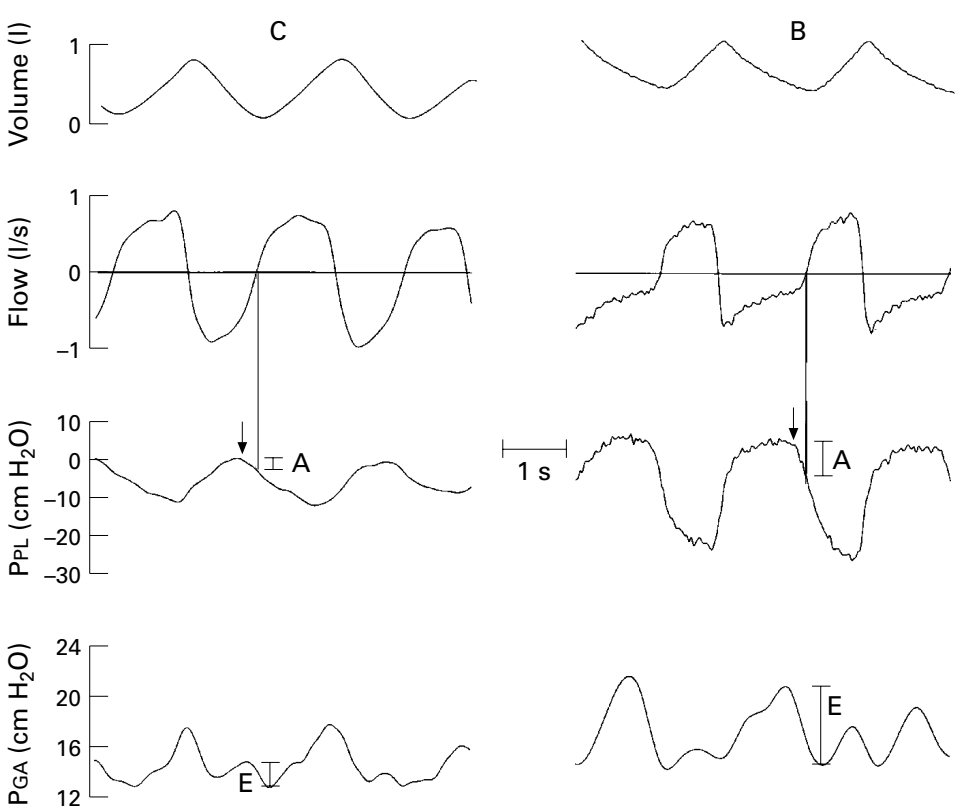

Figure 1 Record of volume (increased upward), flow, pleural pressure (PPL) and gastric pressure (PGA) under control conditions (C) and during acute bronchoconstriction $(B)$ in a representative patient with COPD. The arrows indicate the onset of inspiratory effort and the vertical lines correspond to the onset of inspiratory flow. Dynamic positive end expiratory alveolar pressure was calculated as the negative deflection in PPL (A) that preceded the start of inspiratory flow. The increase in $P_{G A}$ during expiration (E) is also illustrated. was obtained by repeated measurements of inspiratory capacity which was subtracted from TLC measured under control conditions.

Changes in abdominal dimensions were determined using linearised magnetometers. ${ }^{12} \mathrm{~A}$ pair of magnetometer coils was attached on the midline to measure the anteroposterior (AP) diameter of the abdomen $2 \mathrm{~cm}$ above the umbilicus. Changes in the AP diameter of the abdomen during tidal breathing were expressed in arbitrary units.

Mouth pressure (PM) was measured through a side port at the mouthpiece using a differential pressure transducer (Validyne). Oesophageal (Poes) and gastric (PGA) pressures were measured with conventional balloon catheter systems connected to Validyne differential pressure transducers as previously described. ${ }^{13}$ One balloon positioned in the mid oesophagus and containing $0.5 \mathrm{ml}$ of air measured PoEs; the other, positioned in the stomach with the balloon tip $65-70 \mathrm{~cm}$ from nares and containing $2 \mathrm{ml}$ of air, simultaneously measured PGA. PoES was used as an index of pleural pressure (PPL) and PGA as an index of abdominal pressure. Transpulmonary pressure $(\mathrm{PL})$ was obtained by electrical subtraction of PPL from PM.

Total lung resistance was measured during resting breathing using the isovolume method of Frank and coworkers. ${ }^{14}$ To evaluate end expiratory alveolar pressure we used the indirect method rather than the direct method of airway occlusion. ${ }^{1516}$ In fact, awake subjects react to airway occlusion in an unpredictable fashion so that no reliable measurement of alveolar pressure can be obtained. We thus looked for the presence of a time lag between the fall in PPL at the onset of the inspiratory effort and the onset of inspiratory airflow and measured the negative deflection in PPL that preceded the start of inspiratory flow (fig 1). This negative deflection in PPL will be referred to here as dynamic PEEPi for consistency with previous investigations. ${ }^{15}{ }^{16} \mathrm{We}$ also assessed the change in PGA resulting from the contraction of the abdominal muscles during expiration. In agreement with previous studies, ${ }^{24}$ the increase in PGA that occurs during the expiratory phase of the breathing cycle was taken as a reflection of the mechanical effects of abdominal muscle contraction (fig 1). All signals were recorded continuously on a multichannel chart recorder (Gould, TA4000).

(Datex Normocap), and arterial oxygen saturation $\left(\mathrm{SaO}_{2}\right)$ was monitored with an ear oximeter (Radiometer). Histamine administration was discontinued any time one of the following criteria was met: a fall in $\mathrm{FEV}_{1}$ of $>20 \%$ of control and $>0.2 \mathrm{l}$; a fall in $\mathrm{SaO}_{2}$ of $>4 \%$; or enough discomfort or breathlessness to induce the patient to interrupt the test.

Airflow was measured with a no. 3 Fleisch pneumotachograph and a Validyne pressure transducer (Validyne Corporation, Northridge, California, USA), and the flow signal was integrated into the volume. The dead space of the mouthpiece and flowmeter was $70 \mathrm{ml}$ and the resistance of the equipment was $0.92 \mathrm{~cm}$ $\mathrm{H}_{2} \mathrm{O} / 1 / \mathrm{s}$. Assuming that the total lung capacity (TLC) did not change during induced bronchoconstriction, ${ }^{11}$ end expiratory lung volume

\section{PROTOCOL}

Before the experiments each subject was well acquainted with the laboratory and equipment. Lung function tests were performed first. An intravenous line was then established and, after a 20 minute period of rest, $\mathrm{PeTCO}_{2}, \mathrm{SaO}_{2}$, flow, volume, PM, PPL, PGA, and AP diameter of the quiet resting breathing over 20 minutes. Two minutes after each histamine concentration was given measurements during resting breathing were repeated over 2-3 minutes followed by inspiratory capacity and $\mathrm{FEV}_{1}$ assessment.

After completion of measurements of lung function under control conditions no change abdomen were recorded during two periods of 
Table 1 Anthropometric characteristics and pulmonary function data in 14 patients with COPD

\begin{tabular}{|c|c|c|c|c|c|c|c|c|c|}
\hline $\begin{array}{l}\text { Patient } \\
\text { no. }\end{array}$ & $\begin{array}{l}\text { Age } \\
\text { (years) }\end{array}$ & $\begin{array}{l}\text { Weight } \\
(\% I W)\end{array}$ & $\begin{array}{l}F E V_{1} \\
\text { (l) }\end{array}$ & $\begin{array}{l}F E V_{1} \\
\text { (\% pred) }\end{array}$ & $\begin{array}{l}V C \\
(\% \text { pred })\end{array}$ & $\begin{array}{l}F R C \\
(\% \text { pred) }\end{array}$ & $\begin{array}{l}\text { TLC } \\
\text { (\% pred) }\end{array}$ & $\begin{array}{l}\mathrm{PaO}_{2} \\
(k P a)\end{array}$ & $\begin{array}{l}\mathrm{PaCO}_{2} \\
(\mathrm{kPa})\end{array}$ \\
\hline 1 & 69 & 111 & 0.81 & 31.0 & 72.1 & 141.2 & 106.8 & 11.1 & 5.7 \\
\hline 2 & 69 & 118 & 0.83 & 29.9 & 87.2 & 150.6 & 112.7 & 10.0 & 5.8 \\
\hline 3 & 52 & 98 & 1.20 & 38.6 & 91.0 & 136.0 & 105.0 & 10.5 & 5.3 \\
\hline 4 & 58 & 118 & 0.82 & 30.5 & 81.0 & 121.2 & 106.6 & 10.0 & 5.1 \\
\hline 5 & 61 & 114 & 0.81 & 26.2 & 89.6 & 179.4 & 125.6 & 9.2 & 5.9 \\
\hline 6 & 62 & 110 & 1.40 & 49.1 & 101.6 & 114.8 & 111.0 & 12.5 & 5.2 \\
\hline 7 & 74 & 95 & 0.95 & 36.7 & 98.2 & 136.5 & 107.0 & 11.3 & 5.6 \\
\hline 8 & 71 & 118 & 1.30 & 48.5 & 89.2 & 200.2 & 149.6 & 9.5 & 5.7 \\
\hline 9 & 71 & 108 & 0.80 & 33.0 & 124.0 & 160.0 & 130.5 & 10.1 & 5.8 \\
\hline 10 & 63 & 115 & 0.82 & 24.5 & 50.0 & 168.3 & 107.8 & 8.2 & 7.7 \\
\hline 11 & 53 & 109 & 0.85 & 25.3 & 61.5 & 124.9 & 91.1 & 11.4 & 5.7 \\
\hline 12 & 63 & 102 & 1.50 & 48.7 & 95.6 & 202.2 & 151.6 & 10.7 & 5.7 \\
\hline 13 & 64 & 90 & 1.30 & 40.4 & 89.0 & 120.0 & 99.0 & 10.9 & 5.5 \\
\hline 14 & 57 & 120 & 1.45 & 47.3 & 94.0 & 98.0 & 103.8 & 10.5 & 5.6 \\
\hline Mean (SE) & $63.4(2.0)$ & $109(8.5)$ & $1.06(0.08)$ & $36.4(2.6)$ & $87.4(8.2)$ & $146.7(9.2)$ & $114.9(5.2)$ & $10.4(0.3)$ & $5.7(0.2)$ \\
\hline
\end{tabular}

$\mathrm{IW}=$ ideal weight.

in posture was permitted in order to avoid any motion artefact on magnetometer signals. At the end of experiments albuterol was administered by a nebuliser. A physician not involved in the study checked the clinical conditions of the patients throughout the experiments until $\mathrm{FEV}_{1}$ and $\mathrm{SaO}_{2}$ returned to baseline values.

DATA ANALYSIS

Data were averaged for the group of subjects and are presented as means (SE). Data obtained under control conditions and during maximal bronchoconstriction were compared using the Student's $t$ test for paired samples. Changes from baseline values in measured variables during maximal bronchoconstriction are presented as means with $95 \%$ confidence intervals (95\% CI). Single and stepwise multiple regression analyses were performed to assess relationships between variables. The proportion of total variance in the dependent variable accounted for by the predictor variable(s) is reported as the square of correlation coefficient $\left(r^{2}\right)$, expressed as a percentage. A p value of $<0.05$ was considered statistically significant.

\section{Results}

Anthropometric and baseline pulmonary function data of the 14 patients are shown in table 1. Breathing room air, all patients had a $\mathrm{PaO}_{2}$ $>8 \mathrm{kPa}$ and 13 were eucapnic $\left(\mathrm{PaCO}_{2}<6 \mathrm{kPa}\right)$. The geometric mean of the largest concentration of histamine administered was 0.057 $\mathrm{mg} / \mathrm{ml}$. FEV 1 fell by mean of $34.8 \%$ of the control value (95\% CI 29.9 to 39.7$)$ at maximal bronchoconstriction, and this was accompanied by a rise in pulmonary resistance from a control value of $9.9(0.8)$ to $22.8(2.1) \mathrm{cm}$ $\mathrm{H}_{2} \mathrm{O} / 1 / \mathrm{s}$ (mean change $12.9 \mathrm{~cm} \mathrm{H}_{2} \mathrm{O} / 1 / \mathrm{s}, 95 \% \mathrm{CI}$ 8.3 to 17.6 ). End tidal carbon dioxide pressure increased from $5.7(0.2)$ to $6.3(0.3) \mathrm{kPa}$ (mean change $0.6 \mathrm{kPa}$ (95\% CI 0.2 to 1.0 ), $\mathrm{p}<0.05)$, and $\mathrm{SaO}_{2}$ fell from $95.9(0.6)$ to $92.6(1.0) \%$ (mean change $-3.4 \%$ (95\% CI -2.0 to -4.8$), \mathrm{p}<0.001)$.

All patients hyperinflated acutely during bronchoconstriction, the mean increase in end expiratory lung volume being 0.661 (95\% CI
0.49 to 0.83 ; $\mathrm{p}<0.001$; fig 2$)$. Compared with control conditions minute ventilation (VE) remained unchanged during maximal bronchoconstriction (12.2 (0.5) and $11.6(0.9)$ $1 / \mathrm{min}$, respectively) whereas tidal volume decreased from $0.71(0.02)$ to $0.52(0.04) 1$ (mean change $-0.191(95 \% \mathrm{CI}-0.12$ to -0.26 , $\mathrm{p}<0.001$ ) and respiratory frequency (f) increased from $17(1.0)$ to $22(2.5)$ cycles $/ \mathrm{min}$ (mean change 5 cycles/min $(95 \%$ CI 2 to 8 ; $\mathrm{p}<0.01$; fig 2). The increase in respiratory frequency was due to significant reductions both in inspiratory $(\mathrm{p}<0.001)$ and expiratory time $(p=0.01)$.

Plots of the AP diameter of the abdomen versus PGA obtained under control conditions and during maximal bronchoconstriction in two representative patients are shown in fig 3 . Under control conditions in the patient shown in fig 3A inspiration was associated with a progressive rise in PGA and a progressive increase in AP diameter of the abdomen which indicates a shortening and a descent of the diaphragm, whereas during expiration the fall

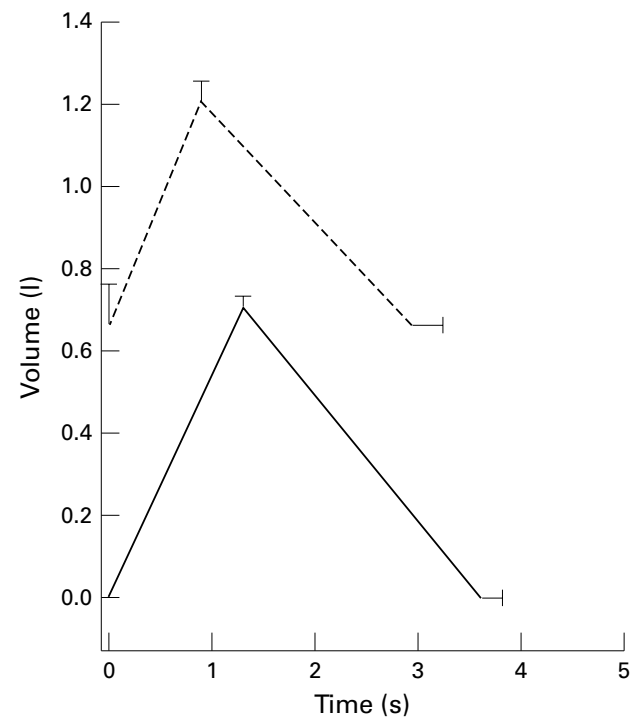

Figure 2 Average breathing pattern under control conditions (continuous line) and during maximal bronchoconstriction (dashed line) in 14 patients with COPD. Bars indicate SE; the zero on the $y$ axis represent end expiratory lung volume under control conditions. 

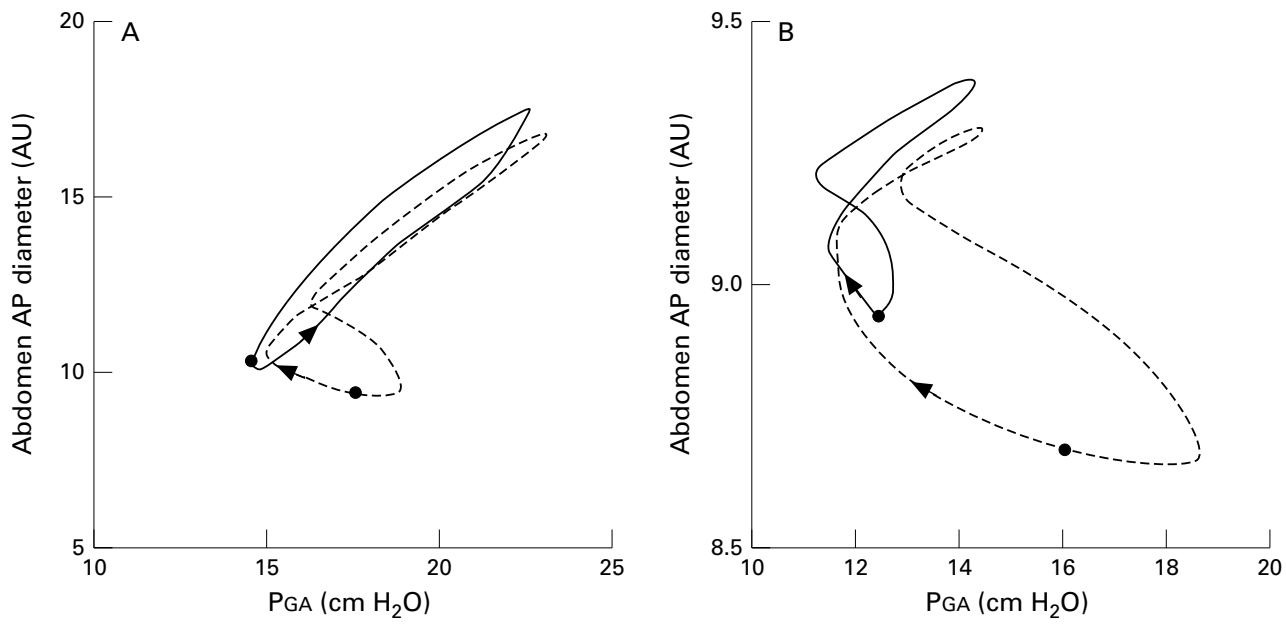

Figure 3 Plots of changes in anteroposterior $(A P)$ diameter of the abdomen versus gastric pressure (PGA) in two representative patients with COPD under control conditions (continuous line) and during maximal bronchoconstriction (dashed line). The closed circles in each panel indicate the end of expiration; the arrows mark the inspiratory phase of the breathing cycles and indicate the direction of the loops. $A U=$ arbitrary units.

in PGA occurred together with a decrease in abdominal AP diameter. The plot of the AP diameter of the abdomen versus PGA in this patient thus had a positive slope and the loop was counterclockwise. This pattern was observed in six of the 14 patients. In contrast, in the patient shown in fig $3 \mathrm{~B}$ under control conditions expiration was characterised by two phases. In the first PGA and abdominal AP diameter decreased in the same way as in the patient in fig 3A, but in the second phase PGA started to rise while the AP diameter of the abdomen continued to decrease, indicating active contraction of the abdominal muscles. As a result of these changes, the plot of abdominal AP diameter versus PGA had a figure of eight pattern. Eight of the studied patients exhibited this pattern under control conditions.

In all patients bronchoconstriction was associated with considerable recruitment of abdominal muscles during expiration. The expiratory rise in PGA increased significantly from $2.0(0.3) \mathrm{cm} \mathrm{H}_{2} \mathrm{O}$ under control conditions to 6.1 (1.0) $\mathrm{cm} \mathrm{H}_{2} \mathrm{O}$ during maximal bronchoconstriction (mean change $4.1 \mathrm{~cm} \mathrm{H}_{2} \mathrm{O}(95 \%$ CI 2.6 to 5.6$), \mathrm{p}<0.001$ ). In eight patients, as in the representative one shown in fig $3 \mathrm{~B}$, most of the rise in PGA during bronchoconstriction occurred during the expiratory rather than the inspiratory phase of the breathing cycle. Just prior to the start of inspiration PGA fell abruptly and continued to fall during the first portion of inspiration whereas the AP diameter of the abdomen increased. In the last portion of inspiration, however, PGA increased again while the AP diameter of the abdomen continued to rise because of the active contraction of the diaphragm. As a consequence, in these patients the plots of PGA versus the AP diameter of the abdomen became mostly clockwise with a negative slope. Abdominal muscle recruitment was also observed in the other six patients. In these patients, however, as shown in the representative example in fig 3A, even during bronchoconstriction most of the rise in PGA continued to occur during the inspiratory phase of the breathing cycle and the plots of the AP diameter of the abdomen versus PGA maintained a positive slope.

As a mean, excursion in the AP diameter of the abdomen during tidal breathing was increased during bronchoconstriction (mean increase $31.8 \%$ of abdominal excursion during tidal breathing in control conditions $(95 \% \mathrm{CI}$ 2.8 to 60.8$), \mathrm{p}<0.05)$. This increase was essentially due to a significant reduction in the $\mathrm{AP}$ diameter of the abdomen at the end of expiration (mean decrease $32.2 \%$ of abdominal excursion during tidal breathing in control conditions (95\% CI 9.5 to 54.9 ), $\mathrm{p}<0.01$ ), the dimension of the abdomen at the end of inspiration being unchanged (fig 4). Fur-

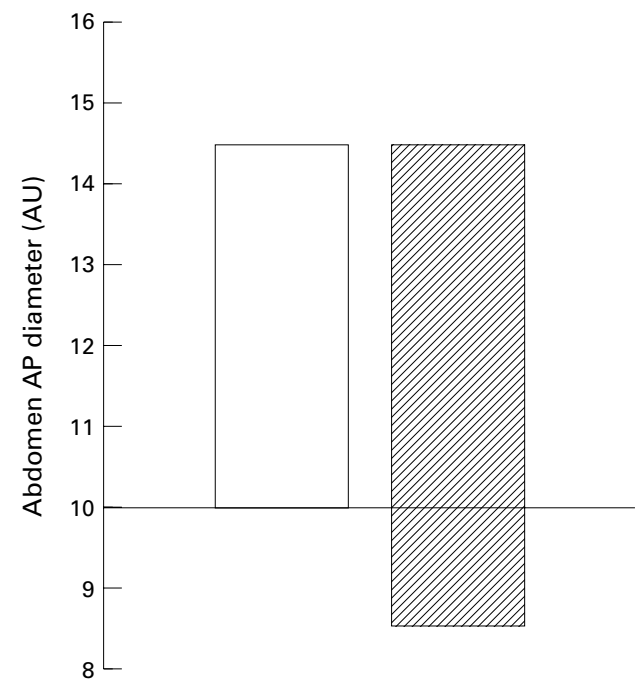

Figure 4 Mean changes in anteroposterior $(A P)$ diameter of the abdomen during tidal breathing in 14 patients with COPD under control conditions (open bar) and during maximal bronchoconstriction (hatched bar). The horizontal line corresponds to the AP diameter of the abdomen at the end of expiration under control conditions. The portion of the hatched bar below the horizontal line represents the reduction in the AP diameter of the abdomen at the end of expiration during bronchoconstriction. 

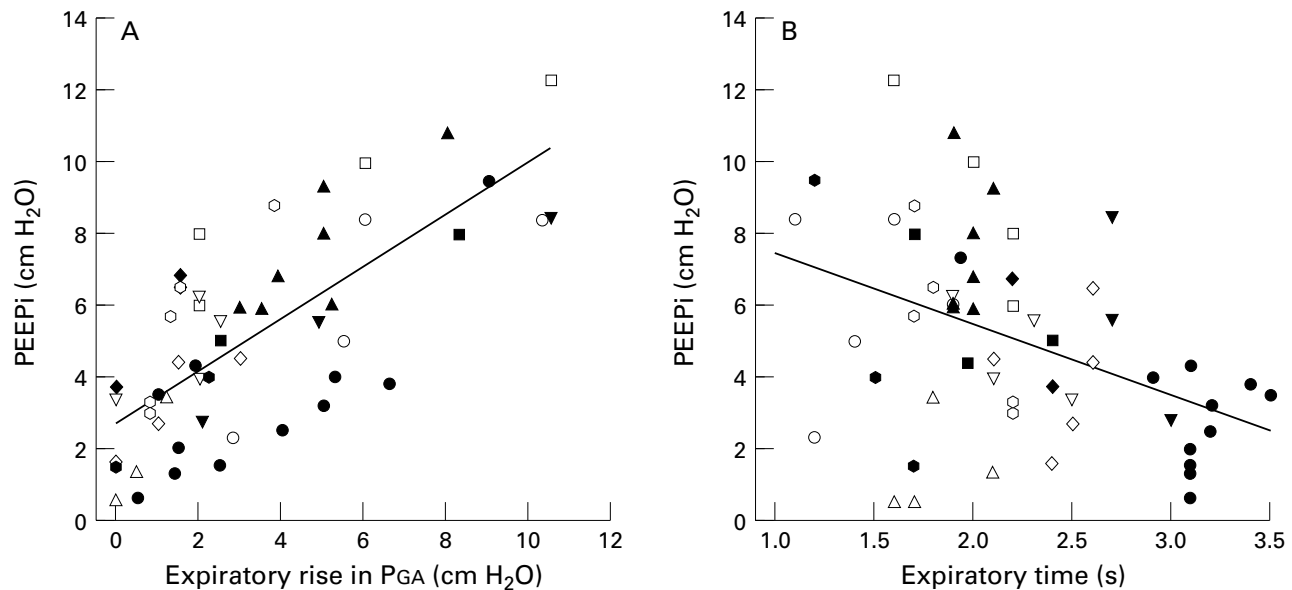

Figure 5 Relationship between dynamic PEEPi and $(A)$ the expiratory rise in gastric pressure (PGA) and $(B)$ the expiratory time during progressive bronchoconstriction in 14 patients with COPD. The solid lines are the regression lines and different symbols correspond to individual patients.

Table 2 Stepwise multiple regression analysis for PEEPi

\begin{tabular}{lclll}
\hline Variable & Coefficient & Model $r^{2}(\%)$ & $F$ & p value \\
\hline PGA & 0.67 & 52.3 & 66.8 & $<0.001$ \\
TE & -1.22 & 57.8 & 7.8 & $<0.01$ \\
Constant & 5.61 & & &
\end{tabular}

$\mathrm{PEEPi}=$ positive end expiratory alveolar pressure; $\mathrm{PGA}=\mathrm{ex}-$ piratory rise in gastric pressure; $\mathrm{TE}=$ expiratory time.

thermore, the AP diameter of the abdomen at the beginning of the rise in PGA during inspiration - that is, at the onset of diaphragm contraction - did not change consistently during bronchoconstriction as it was slightly reduced or unchanged in eight patients and slightly increased in the other six.

Under control conditions dynamic PEEPi was present in all patients but two, with a mean value of $3.0(0.6) \mathrm{cm} \mathrm{H}_{2} \mathrm{O}$. Dynamic PEEPi was significantly greater in the eight patients who showed an expiratory rise in PGA than in the six patients without evidence of abdominal muscle contraction during expiration (4.0 (0.6) and $1.9(0.6) \mathrm{cm} \mathrm{H}_{2} \mathrm{O}$, respectively, $\left.\mathrm{p}<0.05\right)$. During maximal bronchoconstriction PEEPi increased in all patients (mean change $4.4 \mathrm{~cm}$ $\mathrm{H}_{2} \mathrm{O}(95 \%$ CI 3.4 to 5.4$\left.), \mathrm{p}<0.001\right)$. In the patients as a whole, PEEPi during bronchoconstriction was significantly related to the expiratory rise in PGA $\left(r^{2}=52.3 \%, p<0.001\right)$ and expiratory time $\left(r^{2}=15.3 \%, \mathrm{p}<0.01\right.$; fig 5 ) but not to the change in end expiratory lung volume. Stepwise multiple regression analysis showed that expressing PEEPi as a combined function of the expiratory rise in PGA and expiratory time increased slightly the explained variance in PEEPi beyond the contribution of the expiratory rise in PGA. The coefficient and $F$ value of both variables in the final equation, and the model $r^{2}$ as each variable is added, are shown in table 2 .

\section{Discussion}

The main findings of the present study can be summarised as follows: (1) in patients with COPD with severe airflow obstruction acute bronchoconstriction elicited a significant increase in the expiratory rise in PGA and changes in the plots of PGA versus the AP diameter of the abdomen, indicating marked recruitment of abdominal muscles during expiration; (2) abdominal muscle recruitment resulted in a reduction in the AP diameter of the abdomen at the end of expiration such that all of the volume of hyperinflation elicited by bronchoconstriction was incorporated in the rib cage compartment of the chest wall; (3) the increase in dynamic PEEPi during bronchoconstriction was significantly related to the expiratory rise in PGA.

The recruitment of abdominal muscles during bronchoconstriction was evaluated in this study by simultaneously recording PPL, PGA and abdominal displacement, and by the analysis of the plots of the AP diameter of the abdomen versus PGA. The use of volume-pressure plots to infer recruitment of different groups of respiratory muscles has been proposed by Grimby and associates, ${ }^{17}$ and it was subsequently used in normal subjects ${ }^{1819}$ and in patients with COPD. ${ }^{2320}$ The present study did not include electromyographic (EMG) recordings from the abdominal muscles. Our findings clearly show, however, that during bronchoconstriction there was a marked rise in PGA during expiration associated with a decrease in the AP diameter of the abdomen. Hence, compared with the control condition, during bronchoconstriction the volume-pressure loops of the abdomen either became mostly clockwise with a negative slope or had a figure of eight pattern. These alterations, even in the absence of EMG recordings, ${ }^{121}$ clearly indicate that, during bronchoconstriction, patients with COPD with severe airflow obstruction recruited abdominal muscles during expiration to a significant degree.

The mechanisms by which bronchoconstriction induces abdominal muscle recruitment may only be hypothesised. In our patients bronchoconstriction was associated with $\mathrm{CO}_{2}$ retention, as suggested by the increase in $\mathrm{PeTCO}_{2}$, and hyperinflation. Both these fac- 
tors are known to elicit expiratory muscle activation. ${ }^{2223}$ In addition, bronchoconstriction increases the activity of irritant receptors ${ }^{24}$ which may induce expiratory muscle recruitment. ${ }^{23}$ Finally, as recently pointed out by Younes, ${ }^{25}$ abdominal muscle contraction during expiration may be a non-specific natural component of the response of the respiratory system to the increased respiratory stimulus.

As recently discussed by Ninane and colleagues, the usefulness of abdominal muscle contraction during expiration in flow-limited COPD patients remains uncertain. ${ }^{12}$ In the present study, however, we observed that: (1) abdominal muscle recruitment during bronchoconstriction resulted in a decrease in the AP diameter of the abdomen at the end of expiration; (2) the dimensions of the abdomen at the beginning of the inspiratory rise in PGA, which indicates the onset of diaphragm contraction, was unchanged compared with control conditions; (3) bronchoconstriction was associated with an increase in end expiratory lung volume in all patients. Thus, not only all of the volume of hyperinflation induced by bronchoconstriction was incorporated in the rib cage compartment, but this latter also included the volume by which the abdominal compartment decreased. These findings, in line with those obtained during exercise in patients with severe COPD, ${ }^{20}$ suggest that abdominal muscle recruitment during bronchoconstriction allows preservation of diaphragm muscle fibre length and the force generating ability of the diaphragm at the onset of inspiratory muscle contraction, ${ }^{1718}$ in spite of lung hyperinflation.

On the other hand, the distribution of all of the volume of hyperinflation to the rib cage reduces the operational length of the rib cage inspiratory muscles. Although the force generating ability of the parasternal intercostal muscles, the main inspiratory muscles of the rib cage, appears to be greater at a high lung volume than at a low volume, ${ }^{26}$ recent animal studies ${ }^{27}$ suggest that their ability to expand the rib cage and inflate the lung is decreased during hyperinflation due to increased impedance of the ribs to cranial motion. ${ }^{28}$ Recruitment of abdominal muscles during acute bronchoconstriction in patients with severe COPD may therefore have a protective effect on the diaphragm but it may increase the load on the rib cage inspiratory muscles.

Although PEEPi has usually been interpreted as indicating dynamic hyperinflation and used for its quantification, expiratory muscle activity may also increase alveolar pressure at the end of expiration. ${ }^{24}$ Our results show that, under control conditions, PEEPi was significantly greater in the eight patients who had mechanical evidence of abdominal muscle contraction than in those who did not. Furthermore, although there was some variability between patients, a significant relationship was found during bronchoconstriction between the expiratory rise in PGA and PEEPi such that alveolar pressure was greater as the rise in PGA was larger. In line with previous data obtained in patients with COPD breathing at rest ${ }^{24}$ and during mechanical ventilation, ${ }^{29} 30$ these results clearly suggest that PEEPi is, to a significant extent, also related to the transmission, through the relaxed diaphragm, of the rise in abdominal pressure due to abdominal muscle contraction during acute bronchoconstriction. This does not disagree with the concept that dynamic pulmonary hyperinflation increases during acute bronchoconstriction in patients with severe COPD. In our patients bronchoconstriction elicited significant hyperinflation so that end expiratory lung volume was probably higher than the relaxation volume of the respiratory system. Furthermore, PEEPi was also weakly related to expiratory time and, expressing PEEPi as a combined function of the expiratory rise in PGA and expiratory time, increased slightly but significantly the explained variance in PEEPi beyond the contribution of the expiratory rise in PGA. Because positive end expiratory alveolar pressure resulting from expiratory muscle contraction does not represent an inspiratory threshold load, our results suggest that the use of continuous positive airway pressure (CPAP) or external PEEP to reduce inspiratory muscle work in patients with acute exacerbations of COPD require the assessment of abdominal muscle contraction during expiration. In fact, in these patients the use of an excessive level of external PEEP or CPAP may increase hyperinflation with the attendant risks of enhanced shortening of the inspiratory muscles, barotrauma, and haemodynamic compromise. ${ }^{31}$

In conclusion, we have shown that, during acute bronchoconstriction, patients with COPD recruit abdominal muscles to a significant degree during expiration. This recruitment probably preserves diaphragm length despite hyperinflation, but it may increase the load on the inspiratory muscles of the rib cage. It also appears that the active contraction of abdominal muscles during expiration is an important determinant of "PEEPi" so that the degree of dynamic pulmonary hyperinflation during bronchoconstriction may be overestimated.

This study was supported by grants from the Ministero dell’Universita e della Ricerca Scientifica e Tecnologica of Italy

1 Ninane V, Rypens F, Yernault JC, De Troyer A. Abdominal muscle use during breathing in patients with chronic airflow obstruction. Am Rev Respir Dis 1992;146:16-21.

2 Ninane V, Yernault JC, De Troyer A. Intrinsic PEEP in patients with chronic obstructive pulmonary disease. $A m$ Rev Respir Dis 1993;148:1037-42.

3 Martinez FJ, Couser JI, Celli BR. Factors influencing ventilatory muscle recruitment in patients with chronic airflow obstruction. Am Rev Respir Dis 1990;142:276-82.

4 Gorini M, Misuri G, Corrado A, Duranti R, Iandelli I, De Paola E, et al. Breathing pattern and carbon dioxide retention in severe chronic obstructive pulmonary disease. Thorax 1996;51:677-83.

5 Burrows B, Kellog AL, Buskey J. Relationship of symptoms of chronic bronchitis and emphysema to weather and air pollution. Arch Environ Health 1969;16:406-13.

6 Derenne JP, Fleury B, Pariente R. Acute respiratory failure of chronic obstructive pulmonary disease. Am Rev Respir

7 Martin JG, Shore SA, Engel L. Mechanical load and in spiratory muscle action during induced asthma. Am Rev Respir Dis 1983;128:455-60.

8 American Thoracic Society. Standards for the diagnosis and care of patients with chronic obstructive pulmonary diseas (COPD) and asthma. Am Rev Respir Dis 1987;136:225-44

9 Metropolitan Life Insurance Company. New weight standard for men and women. New York: Metropolitan Life, 1983.

10 European Community for Coal and Steel. Standardized lung function testing. Eur Respir f 1993;6(Suppl 16):5-40. 
11 Kirby JG, Juniper EF, Hargreave FE, Zamel N. Total lung capacity does not change during methacholine-stimulated airway narrowing. F Appl Physiol 1986;61:2144-7.

12 Konno K, Mead J. Measurements of the separate volume changes of rib cage and abdomen during breathing. $\mathcal{F} A p p l$ Physiol 1967;22:407-22.

13 Agostoni E, Rahn H. Abdominal and thoracic pressures at different lung volumes. F Appl Physiol 1960;15:1087-92.

14 Frank NR, Mead J, Ferris BJ Jr. The mechanical behaviour of the lungs in healthy elderly persons. F Clin Invest 1957; 36:1680-7.

15 Haluszka J, Chartrand DA, Grassino AE, Milic-Emili J. Intrinsic PEEP and arterial $\mathrm{PCO}_{2}$ in stable patients with chronic obstructive pulmonary disease. Am Rev Respir Dis 1990;141:1194-7.

16 Dal Vecchio L, Polese G, Poggi R, Rossi A. "Intrinsic" positive end-expiratory pressure in stable patients with chronic obstructive pulmonary disease. Eur Respir $\mathcal{F} 1990$; 3:74-80.

17 Grimby G, Goldman M, Mead J. Respiratory action inferred from rib cage and abdominal V-P partitioning. $\mathcal{F} A p p l$ Physiol 1976;41:739-51.

18 Goldman MD, Grimby G, Mead J. Mechanical work of breathing derived from the rib cage and abdominal V-P partitioning. F Appl Physiol 1976;41:752-63.

19 Gorini, M, Duranti R, Misuri G, Valenza T, Spinelli A, Goti $\mathrm{P}$, et al. Aminophylline and respiratory muscle interaction in normal humans. Am F Respir Crit Care Med 1994; 149:1227-34

20 Dood DS, Brancatisano T, Engel LA. Chest wall mechanics during exercise in patients with severe chronic airflow obstruction. Am Rev Respir Dis 1984;129:33-8.

21 De Troyer A, Estenne M, Ninane V, Van Gansbeke D, Gorini $M$. Transversus abdominis muscle function in humans. F Appl Physiol 1990;68:1010-6.
22 Kelsen SG, Altose MD, Cherniack NS. Interaction of lung volume and chemical drive on respiratory muscle EMG and respiratory timing. $\mathcal{F}$ Appl Physiol 1977;42:287-94

23 Oliven A, Chandler Deal E Jr, Kelsen SG, Cherniack NS Effects of bronchoconstriction on respiratory muscle activity during expiration. I Appl Physiol 1987;62:308-14.

24 Vidruk EH, Hahn HL, Nadel JA, Sampson SR. Mechanisms by which histamine stimulates rapidly adapting receptors in dog lungs. F Appl Physiol 1977;43:397-402.

25 Younes $M$. Determinants of thoracic excursions during . Whipp BJ, Wasserman K, eds. Exerise. Pulmonary physiology and pathophysiology. New York: Marcel monary physiology and

26 Jiang TX, Deschepper K, Demedts M, Decramer M. Effects of acute hyperinflation on the mechanical effectiveness of the parasternal intercostals. Am Rev Respir Dis 1989;139: $522-8$

27 Ninane V, Gorini M. Adverse effect of hyperinflation on parasternal intercostals. F Appl Physiol 1994;77:2201-6.

28 De Troyer A, Kelly S, Macklem PT, Zin WA. Mechanic of intercostal space and actions of external and internal intercostal muscles. 7 Clin Invest 1985;75:850-7.

29 Appendini L, Patessio A, Zanaboni S, Carone M, Gukov B, Donner CF, et al. Physiologic effects of positive endexpiratory pressure and mask pressure support during exacerbations of chronic obstructive pulmonary disease. Am ₹ Respir Crit Care Med 1994;149:1069-76.

30 Lessard MR, Lofaso F, Brochard L. Expiratory muscle activity increases intrinsic positive end-expiratory pressure independently of dynan ventilated patients. Am F Respir Crit Care Med 1995;151: $562-9$

31 Marini JJ. Should PEEP be used in airflow obstruction? $A m$ Rev Respir Dis 1989;140:1-3. 